\title{
REPRESENTAÇÕES DO SER PROFESSOR DE QUÍMICA: IDENTIDADE PROFISSIONAL E PROFISSIONALIZAÇÃO DOCENTE
}

\author{
Representations of Being a Chemistry Teacher: Professional Identity and Teacher \\ Professionalization
}

\author{
Franklin Kaic Dutra-Pereira ${ }^{1}$ \\ Michele Marcelo Silva Bortolai ${ }^{2}$
}

\begin{abstract}
Resumo: Ser professor, principalmente de Química, e pensar na identidade desse profissional é a que se volta a este estudo, na tentativa de contribuir com as discussões acerca das representações dadas sobre o pertencimento e o ser docente por licenciandos de química. Sendo assim, objetivamos com esta pesquisa compreender as representações de licenciandos concluintes e ingressantes de um curso de licenciatura em Química acerca do que pensam sobre ser professor(a) de Química. Como aspecto metodológico utilizamos da abordagem qualitativa e descritiva, com preceitos da pesquisa em representação social, com a participação de 30 licenciandos que estavam iniciando e/ou no final do curso de Licenciatura em Química de uma Instituição de Ensino Superior do interior da Bahia. Suas percepções foram submetidas à aplicação Web WordClouds, para criação da nuvem de palavras, evidenciando as significações mais relevantes. Para sistematizar e discutir os dados, realizamos a análise de conteúdo das expressões mais significativas dos grupos. Algumas expressões foram mais expressivas entre os dois grupos investigados, as quais versavam desde a cidadania, passando pela estratégia de ensinar ciências até os desafios da sociedade. Quanto às explicações dadas pelos participantes, emergiram duas dimensões predominantes: "Identidade docente e a profissionalização" e "Identidade docente e a formação para cidadania". Podemos concluir, através das ideias partilhadas pelos futuros professores de Química, que o grupo percebe a importância da formação pedagógica realizada no intercâmbio entre a universidade e a escola caracterizando o papel social da docência e da profissionalização docente, sobretudo voltado para o viés da cidadania.
\end{abstract}

Palavras-chave: Representação Social. Ser professor de Química. Formação Inicial. Identidade Docente.

Abstract: Being a teacher, especially of Chemistry and thinking about the identity of this professional, is that it is turned to this study, to contribute to the discussions about the representations given about belonging and being a teacher by chemistry graduates. Thus, we aim with this research to understand the representation of undergraduates and freshmen from a

\footnotetext{
${ }^{1}$ Curriculista das Ciências, Doutor em Ensino de Ciências, Docente do curso de Licenciatura em Química do Centro de Formação de Professores da Universidade Federal do Recôncavo da Bahia, https://orcid.org/0000-00034486-6124, franklinkaic@ gmail.com

2 Doutora em Ciências, Docente do curso de Licenciatura em Química do Centro de Formação de Professores da Universidade Federal do Recôncavo da Bahia, https://orcid.org/0000-0002-9837-7062, michelemsb@ufrb.edu.br
} 
bachelor's degree in Chemistry about what they think about being a chemistry teacher. As a methodological aspect, we used the qualitative and descriptive approach, with precepts of research in social representation, with the participation of 30 graduates who were starting and/or at the end of the Degree course in Chemistry of a Higher Education Institution in the interior of Bahia. Their insights were submitted to the Web WordClouds application, to create the word cloud, evidencing the most relevant meanings. To systematize and discuss the data, we performed the content analysis of the most significant expressions of the groups. Some expressions were more expressive between the two groups investigated that ranged from citizenship, through the strategy of teaching science to the challenges of society. As for the explanations given by the participants, two predominant dimensions emerged: "Teacher identity and professionalization" and "Teacher identity and citizenship training". We can conclude through the ideas shared by future chemistry teachers, that the group perceives the importance of pedagogical training performed in the exchange between the university and the school characterizing the social role of teaching and teacher professionalization, especially focused on the bias of citizenship.

Keywords: Social Representation. Chemistry Teacher. Initial training. Teacher Identity.

\section{Formação social para a identidade docente}

A formação social para a docência vem sendo discutida, ainda que de forma tímida, entre os pesquisadores da área de ensino, em particular em Ciências da Natureza e suas Tecnologias (ZANON et al., 2010; FEITOSA; BODIÃO, 2015; MALDANER, 1999; SILVA; SCHNETZLER, 2005; FERNANDEZ, 2018; CORRÊA; SCHNETZLER, 2017; GARCIA; KRUGER, 2009). Os estudos realizados por esses pesquisadores tiveram como objetivo trazer um mapeamento do percurso histórico, político, epistemológico, didático e pedagógico da formação de professores de Química no Brasil e no mundo, de modo que não há como essas discussões não adentrarem aos universos escolar e acadêmico. Basta ver os cenários políticos, econômicos, sociais e culturais que inflamam e acenam para uma nova organização dos cursos de licenciatura no Brasil.

As discussões apresentadas por tais pesquisadores e pesquisadoras nos fazem pensar que pouco ou nada contribuíram para a (re)formulação curricular das licenciaturas no nosso país. Trazemos essa constatação atrelando a recente aprovação e futura implementação pelo Conselho Nacional de Educação (CNE), da política nacional de formação inicial e continuada de professores - Base Nacional Comum para a Formação Inicial e Continuada de Professores da Educação Básica (BRASIL, 2019). Esse documento traz em seu bojo uma Base Nacional Comum para os cursos de Licenciatura, a fim de que se tenha uma identidade única e subjetividades removidas e remodeladas pelas políticas neoliberais em que se estabeleceu tal currículo.

Dessa problemática emergem reflexões acerca da formação acadêmica dos licenciandos e seu papel social para a docência, sobretudo pela necessidade de investigar os mecanismos curriculares e as perspectivas atreladas às representações de licenciandos e licenciandas ao escolherem a graduação em um curso de química, bem como às noções eminentes - a curto e longo prazo - sobre a docência em química, principalmente, acerca dos aspectos relacionados à identidade profissional docente.

Vasconcelos, Resque e Barros (2015, p. 23.140) nos dizem que é esse pensamento sobre a formação da identidade profissional que nos mostra a relevância da presença dos licenciandos 
no seu futuro campo de atuação para interação com os demais sujeitos presentes nos espaços escolares, pois é no seu lugar de prática que "[...] representações são construídas, posturas são adotadas e onde são definidas intencionalidades que se identificarão com o jogo social instituído, a partir da pressão das conformidades sociais e da realidade da instituição escolar."

As singularidades da formação inicial docente, neste caso, de Química, se referem, principalmente, ao perfil desses profissionais. Logo, existe uma grande preocupação com “[...] a necessidade de se criar uma comunidade de educadores químicos no Brasil com massa crítica capaz de melhorar a Educação Química em todos os níveis." (MALDANER, 2012, p. 269; ROSSI; FERREIRA, 2012). Essa preocupação se amplia à controvérsia da insuficiência de espaços em campo institucional para a realização dos estágios, lócus de interação entre a universidade e as escolas durante a formação inicial do docente.

A interação entre pares promovida através da realização dos estágios supervisionados possibilita que os licenciandos exerçam o aprendizado acadêmico no âmbito da praticidade, tornando significativas as atividades realizadas pela observação da própria prática. Isso porque as ações praticadas fomentam uma práxis - unidade teoria e prática - relevante no sentido de formar profissionais críticos e atuantes nas unidades escolares. Este universo articula o desenvolvimento cognitivo, as experiências de vida e saberes, além do que está prescrito nas propostas curriculares. Tais aspectos contribuem para que os estágios sejam o ponto central da formação inicial docente.

É a partir dos estágios supervisionados que acontece o diálogo entre o universo acadêmico e o universo escolar. Esse espaço-tempo de ação proporciona a comunicação entre as diferentes esferas do conhecimento, onde o saber é transformado para apropriação e reconstrução significativa pelos licenciandos. Assim, a prática se constitui como momento que transpõe a formação iniciada na universidade e integra tais conhecimentos com as experiências vivenciadas no ambiente escolar. Isso contribui para a formação da identidade dos futuros professores da educação básica.

Deste modo, pensar sobre as relações entre a universidade-escola é uma tarefa complicada, principalmente se considerarmos o tempo-espaço de inserção no contexto escolar que cada estudante vivenciou, trazendo consigo diversas concepções e conceitos a respeito do modus operandi da docência, bem como a sua importância ou não. Tomando isso como base, cabe-nos indagar: que representações os estudantes da licenciatura possuem a respeito de serem professores de Química?

A integração universidade-escola propicia aos licenciandos vivenciar a docência em situações que não seriam imagináveis em outros ambientes, podendo superar os reducionismos presentes em sua formação pela negação da importância de uma sólida formação pedagógica (MIRANDA; PLACCO; REZENDE, 2019). É nesse sentido que ressaltamos a importância das ações realizadas nos estágios supervisionados, que se desenvolvem de maneira dinâmica, pois congregam situações legítimas de ensino e de aprendizagem, se diferenciando em cada contexto escolar.

A formação do docente para atuação nas áreas das Ciências da Natureza não é diferente! Logo, é relevante que os estágios articulem "[...] a formação acadêmica com as práticas escolares; a formação didático-pedagógica com a formação científica [...]." (ZANON et al., 2010, p. 206) para que dessa forma haja a oportunidade de mobilizar aspectos cognitivos e interativos, o que pode levar a desenvolver aprendizados de forma assimétrica, ativa, cultural e social. 
Tais ações são mais flexíveis e atentas às vozes participativas dos licenciandos, pois "[...] é na relação com o outro, numa atividade prática comum, que o sujeito se constitui e se desenvolve como ser humano." (WENZEL, et al. 2010, p. 71). Em outras palavras, é através dessa relação com o outro que os licenciandos constituem sua identidade docente e se afirmam enquanto pesquisadores de Educação em Ciências. Logo, é nesse ínterim ação-reflexão-ação que o licenciando pode se identificar e se reconhecer enquanto docente.

Dubar $(2009,2012)$ traz em seus escritos que a identidade que os indivíduos constroem de si e dos outros se dá por suas interações enquanto parte de um grupo social. Isso desvela o reconhecimento de si e dos outros, conforme o percurso de suas atividades, que são realizadas em torno de um objetivo comum. Entretanto, essa construção identitária pode ser ameaçada por rupturas sociais e/ou econômicas, conferindo descontinuidade de reconhecimento social (TARDIF, 2002), causada "[...] pela precariedade, por baixos salários e falta de qualquer perspectiva de carreira." (DUBAR, 2009; 2012, p. 355), situação também constatada em uma pesquisa realizada por Silva (2019), sobre as condições contratuais de trabalho de docentes da Educação Básica.

Essa aventura de tornar-se professor é um processo contínuo e não se encerra ao final do curso de licenciatura. Este processo nunca pode ser dado como pronto e acabado. Ele perpassa pela dinamicidade e dialogicidade do contexto escolar, legitimando a identidade dos sujeitos (MIRANDA; PLACCO; REZENDE, 2019) em um espaço-tempo de existência de relações profícuas entre a universidade e a escola, entre os saberes dos licenciandos e de seus pares mais experientes.

Para ressaltar a relevância dessa discussão para a formação inicial docente, trazemos à tona o objetivo desta pesquisa: compreender as representações de licenciandos concluintes e ingressantes de um curso de licenciatura em Química acerca do que pensam sobre ser professor(a) de Química de uma universidade pública do interior do nordeste brasileiro. Tomando como referência o objetivo e as questão-problema, a seguir apresentaremos na fundamentação as teorias que utilizamos como suporte em nossa pesquisa.

\section{Olhares críticos para a identidade docente}

Esta seção traz aos nossos olhares a fundamentação teórica que sustenta nossa discussão acerca dos resultados encontrados nesta pesquisa. Assim, conversamos com Serge Moscovici (1978; 2007) e Denise Jodelet (2009) no que se refere a Representação Social da Identidade Docente. Também dialogamos com Pimenta (2000) sobre os modelos de formação docente no Brasil e Tardif (2002) para complementar as especificidades de ser e tornar-se professor no contexto do século XXI.

Moscovici (1978, p. 41) dá significado ao conceito de Representação Social (RS) quando define que "As representações sociais são entidades quase tangíveis. Elas circulam, cruzam-se, e se cristalizam incessantemente através de uma fala, um gesto, um encontro em nosso universo cotidiano. [...] tal como a ciência ou os mitos correspondem a uma prática científica e mítica." Dessa forma, um pensamento social é uma ressignificação da realidade percebida, conforme contextos sociais e experiências vividas. Assim, pensar em uma investigação realizada através de mecanismos próprios da Teoria das Representações Sociais (TRS), acerca do que pensam sobre ser professor os licenciandos de um curso de licenciatura em química, se constitui como um meio de aproximação ao pensamento dos sujeitos sociais que compartilham suas significações acerca de uma identidade comum. 
É nesse sentido que Vasconcellos, Resque e Barros (2015, p. 23.139) discutem acerca da RS da docência, em uma pesquisa realizada com egressos de licenciaturas na área de Ciências da Natureza.

\begin{abstract}
No campo das representações sociais, a docência desponta como processo permanente de construção social decorrente de múltiplas interações dos agentes sociais em seus percursos e contextos de vida. Desta forma, imagens, significados, vivências, experiências e conhecimentos que transitam no pensamento social relativos ao ser professor são construídos, incorporados e reelaborados para a construção da representação da docência.
\end{abstract}

A representação social da docência percorre caminhos que atravessam as interações sociais com a intencionalidade de trazer para si o que está distante, é "A transferência do exterior para o interior, o transporte de um espaço distante para um espaço próximo são operações essenciais desse trabalho cognitivo particular." (MOSCOVICI, 1978, p. 57). Em outras palavras, a representação social significa a compreensão "[...] do mundo concreto, circunscrito em seus alicerces e em suas consequências." (MOSCOVICI, 1978, p. 44), pois o percebido do mundo concreto constitui um prolongamento do vivido em sociedade determinando, desse modo, a realidade instituída na medida em que é própria da nossa cultura.

As representações sociais quando articuladas ao campo educacional configuram a transformação do que está ao seu redor, seja o objeto da significação ou quem faz parte do grupo de pertença do sujeito social. É através das interações, ocorridas no grupo social de pertencimento, que histórias são vividas e práticas sociais são retomadas, em vista a novas acepções de crenças, comportamentos, atitudes e valores já enraizados pelos sujeitos por meio de seu conhecimento de mundo (MOSCOVICI, 2007).

No ambiente escolar, o lócus de aprendizagens e interações sociais não é diferente, pois não se rompem as relações que os sujeitos sociais estabelecem entre si. Nesse espaço-tempo do processo educativo estão presentes diferentes grupos que se unem conforme seus valores e objetivos comuns, e que discurso e prática se justapõem como decorrência do comportamento humano. Assim, é preciso pensar no sujeito como um ser constituído no coletivo do convívio social e não somente na sua individualidade. Como nos afirma Bortolai $(2018$, p. 28):

O contato contínuo entre os indivíduos confere sentimentos partilhados de pertencimento e identidade a um mesmo grupo social. Desse modo, mesmo que os indivíduos não se relacionem fisicamente em seu cotidiano, o pertencimento a uma mesma realidade simbólica de significação de saberes mantém a união entre os sujeitos do grupo.

Moscovici (1978), ao tratar das representações elaboradas pelos sujeitos sociais no diz que essas se formam, principalmente, por meio de observações e do entendimento que se tem sobre elas, se apropriando de suas linguagens e de seu próprio entendimento, através de impressões que permanecem em sua memória, mas que ficam à margem até que se tornem permanentes. Deste modo, ao indagarmos os sujeitos sociais desta pesquisa acerca do que pensam sobre ser professor de química, recebemos como resposta a coletividade de opiniões que são "[...] por um lado, uma fórmula socialmente valorizada a que um indivíduo adere; e, por outro lado, uma tomada de posição sobre um problema controvertido da sociedade." (MOSCOVICI, 1978, p. 46). Portanto, as opiniões dos licenciandos sobre ser e tornar-se professor de Química faz com que se estabeleça uma aproximação entre o estudado no curso 
de licenciatura com as vivências e trajetórias acumuladas no decorrer da vida. Mesmo em um momento histórico-político neoconservador e problemático, entendermos essas opiniões dadas para esta especificidade formativa faz com que

[...] as gerações futuras aprendam sobre si mesmos e sua relação com outros fora de seu mundo, mas também porque eles engajam práticas pedagógicas que são mais que simplesmente técnicas, pois carregam uma natureza moral e política [...] sobre o que afeta suas vidas e seu mundo, potencialmente energizando-os para tornar tais momentos como possibilidades de um novo mundo e para se engajarem em matéria de política, poder e justiça social. (GIROUX, 2006, p. 66, tradução nossa).

Por serem frágeis, a opiniões estão propensas a mudanças influenciadas por prejulgamentos que implicam comportamentos preditivos e que possibilitam inferências sobre as ações dos sujeitos sociais. Assim, as opiniões que se criam a respeito da identidade docente são reflexos internos de uma realidade externa, sendo uma reprodução do que é concebido, como uma extensão do que está ao seu redor, pois só existe em função do conhecimento do objeto, ou seja, da formação da sua identidade docente, que tem a sua gênese no universo social e em suas relações com o mundo (MOSCOVICI, 1978).

Em suas relações com o mundo o sujeito interage e seleciona informações que circulam na sociedade, produzindo comportamentos e não reproduzindo papéis mobilizados pelo universo exterior, com a finalidade substancial de elaboração e interpretação do real. Nas palavras de Moscovici (1978, p. 51), “[...] o comportamento impregna-se de significações, os conceitos ganham cor ou se concretizam [...], enriquecendo a tessitura do que é, para cada um de nós, a realidade.", que a todo instante se transforma.

O diálogo possibilitado pela interação com o outro e diferentes outros no ambiente educacional nos apresenta a relevância dos estágios supervisionados como ponto central na etapa inicial de formação docente. Nesse espaço de ação-reflexão-ação práticas são construídas e compartilhadas e se mostram como o lugar onde os discursos e os saberes dos sujeitos sociais se constituem, ancorando-se a novas ideias e transformando o insólito em familiar. Logo, a constituição identitária do docente se configura como oportunidade e cumplicidade para seu crescimento pessoal e profissional, visto que a formação de sua identidade se dá tanto no interior das universidades quanto no interior das escolas, devido à diversidade de saberes e culturas que ali já se fazem presentes (MOSCOVICI, 1978; 2007; JODELET, 2009).

Nesse sentido, a compreensão de uma realidade social possibilita o entendimento da constituição de um grupo de pertencimento, em que "[...] várias culturas se encontram, se confrontam e se unem [...]" desvelando "[...] como se dão as relações intersubjetivas dos sujeitos sociais com o mundo ao seu redor." (BORTOLAI, 2018, p. 28, 29). Tais relações se modificam em novos contextos e no espaço-tempo da instituição escolar a partir da tomada de perspectiva do outro com quem se interage "[...] sob a forma de evidência cotidiana e de interiorização referentes ao processo pelo qual as normas e valores sociais são integrados no universo interior dos indivíduos." (JODELET, 2009, p. 692).

Também nessa perspectiva, percebemos que a formação docente no Brasil está centrada cada vez mais nas regulações das políticas neoliberais, sobretudo nas avaliações da Educação do país. Se, por um lado, há necessidade de pensar o sujeito íntegro, que se valha de suas açõesreflexões - da práxis pedagógica - como pensar em apenas um único modelo instituído para formação de docentes que vise para além dos aspectos cognitivos? Assim, precisamos observar como estão sendo formados os professores de Química e Ciências no Brasil, para entendermos 
o nosso passado e aprendermos com nossos equívocos/erros, para pensarmos quais as necessidades para se formar professores que atuem na perseverança do futuro. Para além disso, é preciso que haja uma colaboração entre formadores de professores, no que diz respeito à compreensão das perspectivas apontadas pelos discentes ingressantes nos cursos de licenciatura que se contrapõem à ideia de ser docente daqueles concluintes.

Por isso, o saber desses professores sobre ser e tornar-se professor de Química ingressantes e concluintes - é um somatório de suas histórias, de suas trajetórias, de seus pensamentos, de suas vivências, oportunizadas pelas mais de 12 mil horas em período de escolarização e de formação inicial, bem como a interação com os diferentes atores da escola e da universidade que influenciam para o reconhecimento de sua identidade docente.

O saber destes professores não é um conjunto de conhecimentos ou conteúdos cognitivos definidos de uma vez por todas, como algo estático e intocável. Afirmamos, portanto, que é um processo sempre em construção ao longo de toda a carreira profissional, na qual todos os dias se aprende progressivamente a serem e tornarem-se professores. Por sua vez, ocorre a escolha pela Química, a tomada de consciência pela docência em Química, que é influenciada, muitas vezes, pela sua vivência no contexto familiar e nos processos de ensinoaprendizagem na escola. É isso que Tardif (2002) chama de socialização pré-profissional, as experiências de outrem que influenciam a escolha pela docência.

Portanto, entendemos a necessidade de compreendermos as representações de estudantes que estejam em contexto de estágio supervisionado ou que estejam iniciando o curso de Licenciatura em Química, para que possamos refletir sobre que/quais saberes e conhecimentos, enquanto pensadores-pesquisadores-curriculistas, estamos valorizando nos currículos dos cursos de formação inicial: as histórias de vida, as trajetórias e as concepções sobre a docência?

Defendemos também que os Projetos Pedagógicos dos Cursos de Licenciatura devem contemplar em seus currículos estratégias que possam contribuir para a construção da identidade docente, a partir da consideração de saberes necessários ao ensino e das histórias de vida, numa perspectiva formativa que assuma a escola e as vivências das trajetórias de vida como eixo central da formação do profissional docente. Sendo assim, discorreremos a seguir sobre as escolhas metodológicas que fizemos ao nos aventurarmos pelos caminhos investigativos para compreendermos as representações sociais dos estudantes em início do curso e estagiários em final de curso sobre o que é ser professor de Química.

\section{0 caminho investigativo do Ser Professor de Química}

Esta pesquisa de abordagem qualitativa descritiva (BOGDAN; BIKLEN, 1994; LÜDKE; ANDRÉ, 1986) foi realizada em duas etapas com 30 licenciandos de um curso de Licenciatura em Química de uma universidade pública do interior da Bahia. A primeira etapa foi realizada em dezembro de 2019, com 07 licenciandos concluintes, durante um curso de extensão intitulado I Ciclo de Debates: Pesquisas em Educação Química, que teve por finalidade ampliar a compreensão dos licenciandos sobre a importância da pesquisa para a formação docente. Estes estudantes estavam concluindo o curso, matriculados no Estágio Supervisionado em Química III, que eram orientados por um dos autores deste artigo.

A segunda etapa foi realizada em fevereiro de 2021 - de modo remoto devido ao isolamento social causado pela pandemia da COVID-19 - com 23 licenciandos ingressantes, no início das aulas do componente curricular Introdução aos Estudos Acadêmicos em Química. Este componente de caráter obrigatório para o cumprimento da carga horária do curso, também 
ministrado pela mesma docente, teve por fim debater questões relativas à pesquisa científica em Educação Química e sua importância na formação inicial do docente para atuação na Educação Básica.

Para garantir o anonimato dos sujeitos investigados pelo RESSONAR - Coletivo Universitário de Pesquisa em Representação Social, Narrativas [auto(bio)gráficas] e Argumentação em Educação Científica ${ }^{3}$, não utilizamos seus nomes reais. Logo, os estudantes foram chamados por licenciandos concluintes e licenciandos ingressantes. Os licenciandos participantes assinaram o Termo de Consentimento Livre e Esclarecido (TCLE), o que possibilitou que dissertassem livremente ao imprimirem seus pensamentos, sem interrupções e constrangimentos por meio do Google Forms. Assim, numa lógica de levantamento das ideias prévias optamos pelo questionário de resposta aberta através das expressões indutoras "Para mim, ser professor de química é ..., pois ..." (para o grupo de licenciandos concluintes) e "O que eu penso sobre ser professor(a) de Química" (para o grupo de licenciandos ingressantes), revelando as expressões induzidas (BARDIN, 2016) mais significativas para os grupos.

As palavras foram submetidas a uma aplicação Web WordClouds ${ }^{4}$, para criação da nuvem de palavras (uma maneira gráfica de sumarizar informação), com o objetivo de destacar os termos (induzidos) mais frequentes no construto dos futuros professores de Química.

A técnica utilizada para análise dos dados foi organizada conforme o proposto por Bardin (2016) para Análise do Conteúdo, onde se busca compreender as mensagens expressas através das categorias criadas a posteriori, conforme aproximação semântica e após procedimentos exploratórios para dimensionar as análises a que este trabalho se propõe, fazendo emergir sob a luz dos referenciais teóricos, as impressões iniciais que conduziram as análises.

\section{0 que pensam os futuros docentes sobre Ser Professor de Química}

A seguir apresentamos a sistematização dos dados obtidos por meio das questões indutoras: "Para mim, ser professor de química é ..., pois ..." (para o grupo de licenciandos concluintes) e "O que eu penso sobre ser professor(a) de Química" (para o grupo de licenciandos ingressantes). Assim, nas nuvens de palavras apresentadas nas Figuras 1 e 2 mostram-se as expressões mais significativas nas representações.

Para o grupo de licenciandos concluintes as ideias partilhadas mais expressivas foram: professor, alunos, sociedade, cidadãos, química e estratégias. Já para o grupo de licenciandos iniciantes temos as expressões em destaque: alunos, matéria, área, difícil, profissão, ensinar, ciências e desafio. Essas ideias partilhadas em cada grupo social representam a significação da construção da identidade do professor de química e os saberes necessários à sua prática.

Os resultados encontrados inicialmente nos indicam diferenças nas representações dos dois grupos de licenciandos, que estão refletidas nas configurações das nuvens de palavras construídas.

\footnotetext{
3 O RESSONAR, enquanto grupo de pesquisa em Educação Científica, tem por objetivo socializar saberes e conhecimentos voltados ao contexto de nossas investigações em representações sociais, narrativas [auto(bio)gráficas] e argumentação em educação em ciências, a fim de contribuir com as discussões emergentes acerca da formação docente e dos processos de ensino-aprendizagem, considerando a sociedade pós-moderna.

4 Disponível em: https://www.wordclouds.com/
} 
Figura 1 - Ideias partilhadas pelos licenciandos concluintes acerca do que pensam sobre ser professor(a) de Química.

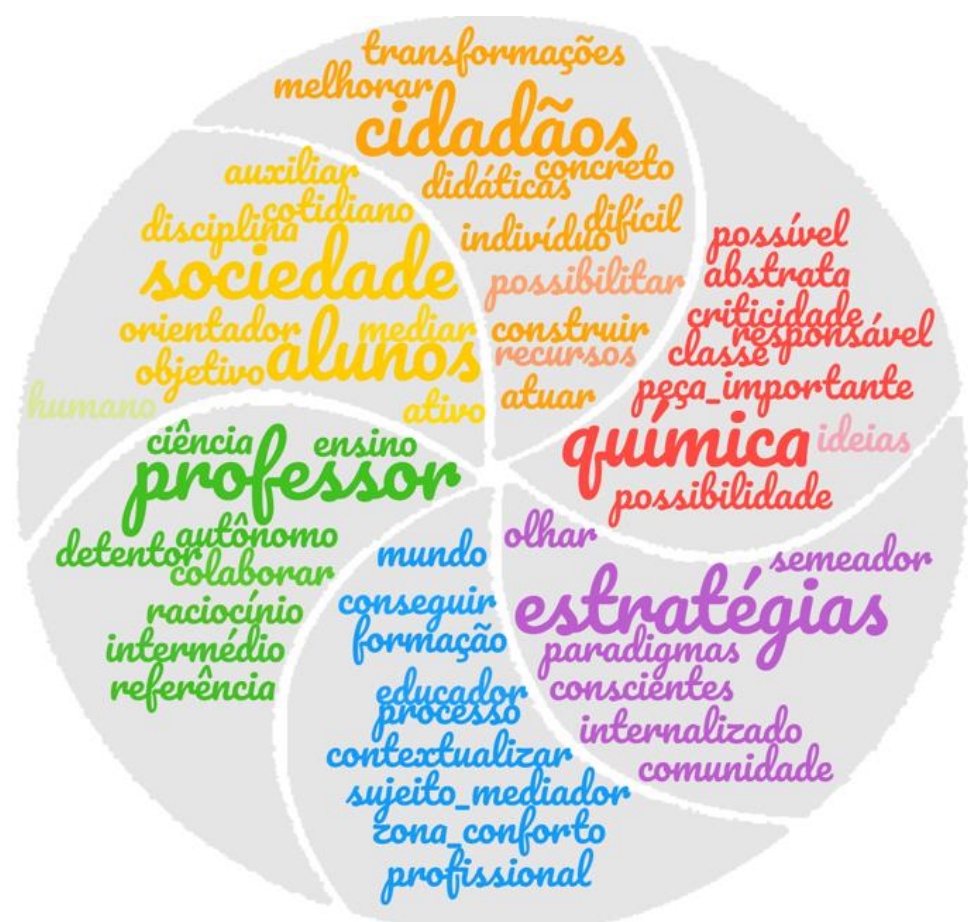

Fonte: elaborada pelos autores e desenvolvido em https://www.wordclouds.com/)

Figura 2 - Ideias partilhadas pelos licenciandos ingressantes acerca do que pensam sobre ser professor(a) de Química.

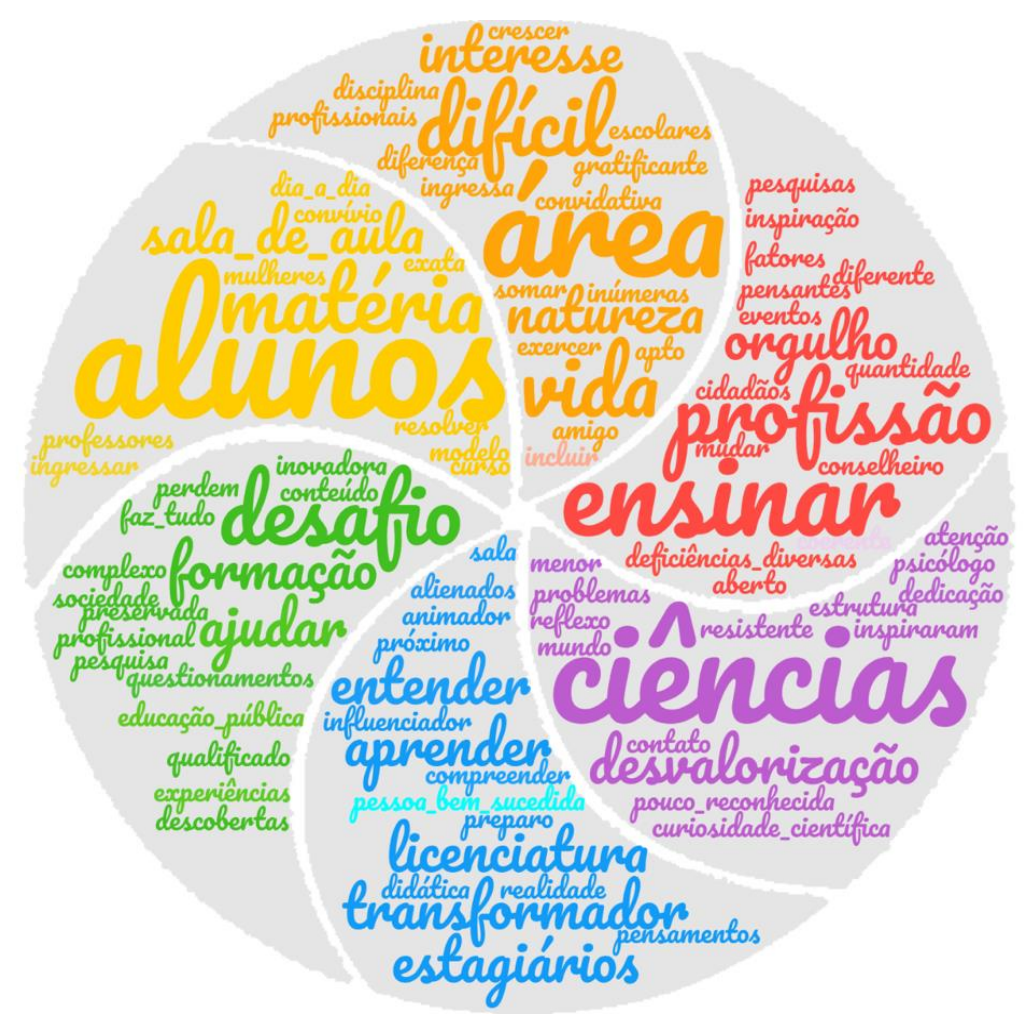

Fonte: elaborada pelos autores e desenvolvido em https://www.wordclouds.com/) 
Segundo Moscovici (1978; 2007) e Jodelet (2009), as representações de diferentes grupos sociais são fenômenos que se formam no cotidiano dos indivíduos, através de sistemas subjetivos de interpretação e comunicação, que norteiam as relações dos indivíduos com os que estão ao seu redor. Desse modo, as representações direcionam e interferem em diferentes processos, como na assimilação de conhecimentos, na formação da identidade profissional e/ou pessoais formadas por um grupo ou mesmos nas transformações sociais (MENEZES, 2017).

Daí parte a compreensão que apenas uma parcela dos licenciandos consideram a Química enquanto Ciência que faz parte de um contexto social destacando em suas proposições uma visão mais dinâmica e crítica de sua formação e atuação como docentes. Essas representações podem ser reproduzidas nas aulas da Educação Básica de modo a promover uma Educação Científica através de uma imersão no saber experiencial, denotando a necessidade das vivências de/sobre a docência (PIMENTA, 2000; TARDIF, 2002). Nas palavras dos licenciandos concluintes:

Para mim ser professor de química é auxiliar no processo de ensino aprendizagem de química para que os estudantes se interessem por esta ciência, pois por ser disciplina tida como difícil e abstrata, deve-se tentar aproximá-la do concreto (cotidiano).

Para mim ser professor de química é ser um profissional responsável pelo intermédio entre o conhecimento científico acadêmico e a comunidade, pois através de práticas pedagógicas é possível melhorar o sistema educacional que por sua vez afeta o comportamento humano.

Outros licenciandos, entre concluintes e ingressantes, trazem uma ideia menos crítica do papel do professor, quase que numa visão tradicional do ensino, pois condicionam a questão do ser professor à posição de um profissional qualificado, detentor de um conhecimento que vai além de seu preparo didático-pedagógico para manutenção do interesse dos estudantes pela compreensão do objeto de aprendizagem.

Para mim ser professor de química é ser semeador de ideias e orientador, além de ser o detentor do conhecimento químico, pois o professor de química, como todos os professores de forma geral, é a maior referência para os alunos fora da classe.

Eu penso que é um desafio, o professor está em contato com diversos tipos de pessoas com pensamentos e comportamentos diferentes em uma sala de aula. Química é uma matéria exata esse desafio aumenta ainda mais, pois o professor de química vai precisar de muita didática e também vai exigir muita atenção dos alunos para entender a matéria.

Penso que este quando ingressa em uma formação para professor ele estará apto a ser este profissional, porém o seu campo de conhecimento não se restringe ao ser um docente uma vez que a química é uma área que se enquadra em vários aspectos da sociedade

É uma área maravilhosa, apesar de eu nunca ter me interessado nisso, sempre admirei os professores por suportarem e fazerem o seu trabalho.

Uma pessoa bem-sucedida e que possa passar seu conhecimento para o próximo.

Nesse sentido, Menezes (2017, p. 88) nos afirma que a RS é uma representação que se expressa simbolicamente como "[...] leva a marca do sujeito e de suas ações. Assim, as atitudes do sujeito dizem respeito ao caráter construtivo, criativo, autônomo da representação que 
contém uma parte de reconstrução, de interpretação do objeto e de expressão do sujeito." Podemos inferir, deste modo, que as contradições encontradas nas representações se justificam pela participação de alguns licenciandos nos estágios supervisionados, sendo este um elemento diferencial em sua formação. Essa observação já era esperada, considerando as vivências/experiências e as culturas estabelecidas durante a Educação Básica, sobretudo no Ensino Médio, além do fato de parte dos licenciandos iniciantes ainda não terem vivenciado o espaço escolar e a interação com seus pares, influenciando diretamente a representação de suas identidades docentes.

Nesse caminho de análise dos dados encontrados foi realizada a análise de conteúdo, conforme proposto por Bardin (2016), iniciada pela leitura flutuante, depois a lematização, codificação e, por último, a criação de duas dimensões de análise predominantes: Identidade docente e a profissionalização e Identidade docente e a formação para cidadania, as quais estão definidas no Quadro 1.

Quadro 1 - Sistematização dos dados

\begin{tabular}{|c|c|c|}
\hline Objetivo investigativo & Dimensões & Definições \\
\hline $\begin{array}{c}\text { Compreender as representações de } \\
\text { licenciandos concluintes e ingressantes de } \\
\text { um curso de licenciatura em Química acerca } \\
\text { do que pensam sobre ser professor(a) de } \\
\text { Química }\end{array}$ & $\begin{array}{c}\text { Identidade docente e a } \\
\text { profissionalização }\end{array}$ & $\begin{array}{c}\text { Contribuições das trajetórias para a } \\
\text { escolha profissional e bases teóricas, } \\
\text { políticas e filosóficas da formação } \\
\text { docente }\end{array}$ \\
\cline { 2 - 3 } & $\begin{array}{c}\text { Identidade docente e a } \\
\text { formação para a } \\
\text { cidadania }\end{array}$ & $\begin{array}{c}\text { Condições e possibilidades da } \\
\text { formação inicial de professores de } \\
\text { Química e as bases epistêmicas e } \\
\text { metodológicas da formação docente }\end{array}$ \\
\hline \multicolumn{2}{|c|}{} \\
\hline
\end{tabular}

Fonte: elaborada pelos autores

Pelo exposto até aqui, concluímos que realizar a leitura e a análise das respostas dos estudantes em início de curso e daqueles que estão se formando - estagiários - nos permitiu identificar não somente fatos pontuais das representações e/ou analisar com mais profundidade aspectos específicos da formação inicial de professores de Química, possibilitou, ainda, visualizarmos a complexa rede de saberes, teorias e práticas que contribuem para a formação docente ao longo da vida. As diferentes representações sobre ser professor de Química podem ser encaradas como um balanço da formação, que aponta para possíveis linhas teórico-práticas da atuação docente, conforme detalharemos a seguir.

\subsection{Identidade docente e a profissionalização}

Nesta dimensão de análise agrupamos as justificativas que apresentam a representação da identidade docente e sua profissionalização por meio do reconhecimento de suas trajetórias e da formação profissional de professor, o que contribui para suas escolhas profissionais e para as discussões sobre as bases teóricas, políticas e filosóficas da formação docente. Destacamos que nesse processo de profissionalização e formação da identidade docente muitos estudantes elencaram justificativas pensadas a partir dos saberes docentes descritos por Pimenta (2000) e 
Tardif (2002) em que se torna fulcral não apenas a aprendizagem do conteúdo, mas dos diferentes campos formativos. Para mim ser professor de química é quebrar os paradigmas, ter um olhar educador,
utilizar estratégias didáticas, contextualizar o ensino de química, pois ser professor
é sair da sua zona de conforto, é tornar o aluno autônomo.

Penso que ser professor de química é algo que requer bastante preparo e dedicação, pois muitos dos alunos perdem o interesse na disciplina simplesmente por não ter um professor bem qualificado.

Baseado nas minhas experiências escolares tenho muito orgulho e inspiração pelos profissionais da área, desde os estagiários ao meu professor me inspiraram a ingressar nesse curso, mesmo com dificuldades, seja pela menor quantidade de mulheres na área ou a desvalorização da ciência.

O ensino da química é muito importante, pois ajuda a entender diversos fatores que acontecem na natureza quanto no dia a dia. Então considero que ser professor de química é muito importante para ajudar a compreender muitos eventos.

Eu penso que ser professor (a) de química é ensinar e sempre aprender mais e mais seja através de pesquisa na área da química quando em convívio em sala de aula.

Ser coerente, e estar aberto às possibilidades de passar conhecimento, e crescer mais questionamentos.

Eu penso que é um pouco complexo, pela falta de estrutura na educação pública e a desvalorização da ciência pelos alunos (na sua maioria), mas estamos aqui para mudar essa realidade.

Ser professor é ser um modelo na vida de muitos estudantes principalmente na química que é uma matéria em que muitos alunos demonstram dificuldade é importante que o professor saiba trazer o conhecimento de uma forma que facilmente seja entendida.

Essas representações corroboram os estudos realizados por Alves-Mazzotti (2007, p. $587,588)$ ao trazer à tona a questão dos desafios e dificuldades enfrentados pelos docentes em sua profissão. Ao falarem sobre suas representações sobre a identidade docente remetem à questão da desvalorização profissional, tanto em relação à falta de estrutura da educação pública quanto à desvalorização da ciência. Em outras palavras, "A este sentido idealizado da profissão, fundado em valores, modelos, símbolos e estereótipos tradicionais, a realidade da prática atual vem opondo outro, que prenuncia uma transformação da representação de ser professor [...].”. $\mathrm{Ou}$ ainda, as representações sobre a identidade docente "[...] expressam sentidos tradicionalmente ligados à função docente, mas que parecem estar perdendo força diante das dificuldades encontradas no cotidiano escolar."

O processo de reflexão sobre a prática docente pode estar associado com o saber experiencial, aquele que é construído pelo próprio docente a partir das suas relações. Esse processo de reflexão tem grande importância para a profissionalização, uma vez que direciona o docente para análise de suas práticas e faz com que possa repensar sobre seus limites e potencialidades.

Percebemos também que esses profissionais em formação buscam a construção da sua identidade a partir de um olhar para a sua experiência discente na Educação Básica ao afirmar a química como sendo uma disciplina difícil e que por isso o ser professor de química perpassa pela utilização da contextualização no processo de ensino aprendizagem de química. Conforme aponta Tardif (2002) esse saber experiencial é o único construído pelo professor a partir de suas 
experiências discentes e docentes e, por isso, trata-se de um saber tão significativo. Este apontamento se coaduna ao apresentado por Moscovici $(1978$; 2007), ao nos dizer que as representações são elaboradas e compartilhadas por um grupo social, neste caso de licenciandos, que influenciam as representações formadas por observação da realidade experienciada, vivida e percebida. Em outras palavras, segundo Dubar (2009), as identidades são construídas e reconstruídas ao longo da vida, envolvendo conflitos relacionados a suas histórias e perspectivas.

Em diferentes justificativas é possível perceber características de uma educação não para emancipação, mas para o processo de se tornar professor. Esta é uma apropriação que é transferida e então alguém adquire. A representação da identidade docente perpassa ainda pela compreensão de que o professor não é aquele que apenas conhece o conteúdo a ser ensinado (saberes disciplinares), mas também aquele que orienta.

\subsection{Identidade docente e a formação para a cidadania}

Nesta dimensão de análise agrupamos as justificativas que apresentam a representação da identidade docente e sua formação para a cidadania por meio do reconhecimento das condições e possibilidades da formação inicial de professores, o que contribui para as discussões sobre as bases epistêmicas e metodológicas da formação docente. Destacamos que nesse processo de representação da identidade docente muitos estudantes elencaram justificativas pensadas a partir de uma realidade idealizada, com uma ênfase no socialmente desejável.

Para mim ser professor de química é mediar conhecimento promovendo a criticidade e raciocínio, pois o professor por si só não garante que o conhecimento seja internalizado.

Para mim ser professor de química é conseguir possibilitar com que o aluno seja ativo na sociedade em que está inserido e entender o mundo que o cerca através da química, pois o professor é uma peça importante na formação cidadã do aluno.

Para mim ser professor de química é atuar como sujeito mediador, para que os alunos tenham a possibilidade de construir conhecimento, utilizando estratégias e recursos para que se possa atingir o objetivo, pois o professor é um indivíduo que colabora com transformações na sociedade, forma cidadãos conscientes.

Ser resistente, influenciador de forma negativa ou positiva, um faz "tudo" mesmo que sua formação seja em licenciatura o professor tem que aprender a incluir pessoas com graus de deficiências diversas, resolver problemas de sala, ser psicólogo, conselheiro, amigo. Ter essa profissão é exercer inúmeras outras além de uma licenciatura. Ensinar aos alunos que a natureza precisa ser preservada, que eu possa desenvolver sua curiosidade científica.

É um agente transformador formando agentes transformadores.

Saber que eu posso fazer diferença na vida de outras pessoas e que posso ajudar a formar cidadãos pensantes e não alienados é muito animador.

Diante das justificativas apresentadas pelos licenciandos, foi possível observar que existe certa preocupação com a formação da identidade docente em uma perspectiva cidadã em que o tornar-se professor de Química estava muitas vezes associado com a relação da ciência Química com a cidadania. 
Ressaltamos que este cuidado de pensar o professor com essa perspectiva voltada às características humanísticas-sociais traz inúmeros benefícios para que a Educação Básica seja articulada com a finalidade da Educação prevista na Lei 9.394 de 1996 - Lei de Diretrizes e Bases da Educação Nacional (BRASIL, 1996), além do que orienta os demais documentos oficiais que norteiam a Educação.

Pensar a identidade docente na perspectiva cidadã nos leva a observar as relações entre universidade-comunidade, formação docente e sociedade, química e cidadania. Desse modo, compreendemos, à luz de Santos (2011), que as representações dos licenciandos em relação à cidadania apresenta suas raízes em contextos históricos diferentes, apontando para ideais progressistas, pautando-se na ideia mais promissora, humanista, pertencente ao contexto sóciohistórico-cultural-econômico-político que, por sua vez, contribuirá na compreensão de saberes e conhecimentos formativos durante e após o percurso da Licenciatura em Química. Porém, como nos aponta Santos (2011, p. 302), “[...] para isso, é preciso desenvolver a participação dos estudantes para que eles se engajem nas decisões da cidade. É assim que concebemos uma educação para a cidadania como educação para tomada de decisão, o que implica na necessidade de desenvolver a faculdade de julgar."

Portanto, a defesa que fazemos a partir das representações dos licenciandos e do nosso referencial teórico é uma educação química para a sociedade, valorizando os diversos conhecimentos da cidadania, pois os conhecimentos científicos se concretizam à medida que são (inter)relacionados com as demandas emergentes da sociedade e não através das imposições neoliberais-econômicas e políticas.

\section{Considerações finais}

Existem diversas implicações a serem discutidas quando pensamos no Ensino de Química e na formação docente. Pensar sobre o que, por que e para quem ensinar Química envolve práticas docentes e o reconhecimento das necessidades cotidianas dos estudantes. Decerto que situações diferenciadas e que fogem ao habitual, muitas vezes, são constituídas de características que extrapolam as possibilidades de mediações que a instituição educacional ou mesmo o professor possuem.

Em decorrência dessa situação reflexões mais abrangentes modificam e ampliam a relação das escolas com as universidades. Uma compreensão mais significativa dessa interface escola/universidade abrange conhecer suas histórias e as dinâmicas sob as quais se constituem o seu cotidiano e as representações que a partir dessa interface se formam, especialmente, no que se refere à herança cultural e à gestão da diversidade na sala de aula.

Isso significa mudanças nas práticas pedagógicas e nas relações existentes no interior das escolas para justificar as necessidades de uma sociedade em constante transformação social.

Vale ressaltar que a consolidação da formação da identidade docente não se subsidia apenas em conhecimentos científicos. Ela visa à formação de cidadãos autônomos, capazes de realizar transformações no ambiente que os cerca. Devem-se considerar, para tanto, aspectos voltados às questões sociais e de interesse público, que se diferenciam do caráter estritamente científico.

Assim, as justificativas dos licenciandos trazem não somente pistas das suas representações sobre ser professor de química, mas também nos dão margem para uma necessidade de valorizar nos currículos formativos, sobretudo nos estágios, os conhecimentos e saberes que os estudantes têm. É necessário que ocorra tal valorização para os licenciandos não se sentirem sujeitos a-históricos e atemporais. Percebemos, portanto, que as representações 
dos licenciandos são marcas históricas de seu percurso formativo. Além disso, temos em mente que as análises e discussões que fizemos estão longe de serem esgotadas, porém a riqueza com as quais as representações se apresentam pode suscitar diversos outros questionamentos e/ou debates para que se possa sempre melhorar a formação docente e o ensino de Química para/na cidadania.

\section{Referências}

ALVES- MAZZOTTI, Alda Judith. Representações da identidade docente: uma contribuição para a formulação de políticas. Ensaio: aval. pol. públ. Educ., Rio de Janeiro, v. 15, n. 57, p. 579-594, out./dez. 2007.

BARDIN, Laurence. Análise de conteúdo. Trad. Luís Antero Reto, Augusto Pinheiro São Paulo: Edições 70, 3ª reimp., 2016.

BOGDAN, Robert; BIKLEN, Sari. Investigação Qualitativa em Educação: uma introdução à teoria e aos métodos. Portugal: Porto, 1994.

BORTOLAI, Michele Marcelo Silva. Percepções escolares sobre Água na perspectiva da Teoria das Representações Sociais. 2018. Tese (Doutorado em Ensino de Química) - Ensino de Ciências (Física, Química e Biologia), Universidade de São Paulo, São Paulo, 2018. doi:10.11606/T.81.2019.tde-03052019-155345. Acesso em: 2021-10-12.

BRASIL. Lei de Diretrizes e Bases da Educação Nacional. LDB. 9394/1996. Brasil.

BRASIL. Ministério da Educação. Base Nacional Comum da Formação de Professores da Educação Básica. Brasília, 2019.

CORRÊA, Thiago H. Barnabé; SCHNETZLER, Roseli Pacheco. Da formação à atuação: obstáculos do tornar-se professor de química. Revista Debates em Ensino de Química, v. 3, n. 1, 2017. Disponível em:

http://www.journals.ufrpe.br/index.php/REDEQUIM/article/view/1356. Acessado em: 30 ago. 2021.

DUBAR, C. A. Construção de si pela atividade de trabalho: a socialização profissional. Cadernos de Pesquisa, v. 42, n. 146, p. 351-367, 2012.

DUBAR, C. A crise das identidades: a interpretação de uma mutação. São Paulo: EDUSP. 2009. 296p.

FEITOSA, Raphael Alves; BODIÃO, Idevaldo da Silva. As teorias sobre o "professor reflexivo" e suas possibilidades para a formação docente na área de Ciências da Natureza.

Revista entreideias, v. 4, n. 1, 2015. Disponível em: https://periodicos.ufba.br/index.php/entreideias/article/view/9776/9485. Acessado em: 30 ago. 2021.

FERNANDEZ, Carmen. Formação de professores de Química no Brasil e no mundo. Estudos avançados. v. 32, n. 94, 2018. Disponível em: https://doi.org/10.1590/s0103-

40142018.3294.0015. Acessado em 30 ago. 2021. 
GARCIA, Irene T. Santos; KRUGER, Verno. Implantação das diretrizes curriculares nacionais para formação de professores de química em uma instituição federal de ensino superior: desafios e perspectivas. Química Nova, v. 32, n. 8, 2009. Disponível em: https://doi.org/10.1590/S0100-40422009000800039. Acessado em: 30 ago. 2021.

GIROUX, Henry A. Higher Education under Siege: Implications for Public Intellectuals. Thought \& Action, Fall, p. 63-78, 2006. Disponível em: https://web.archive.org/web/20180411220334id_/http://www.nea.org/assets/img/PubThought AndAction/TAA_06_08.pdf.Acessado em: 30 ago. 2021.

JODELET, Denise. O movimento de retorno ao sujeito e a abordagem das representações sociais. Soc. estado., Brasília, v. 24, n. 3, p. 679-712, Dec. 2009. Disponível em: <https://www.scielo.br/j/se/a/bqm4vwYnbPvPy9dDGMWHqZt/?lang=pt>. Acesso em: 27 ago. 2021.

LÜDKE, Menga; ANDRÉ, Marli D. Afonso. Pesquisa em Educação: abordagens qualitativas. São Paulo: EPU, 1986.

MALDANER, Otavio Aloisio. A pesquisa como perspectiva de formação continuada do professor de química. Química Nova, v. 22, n. 2, 1999. Disponível em: https://doi.org/10.1590/S0100-40421999000200023. Acessado em: 30 ago. 2021.

MENEZES, Mayara Aparecida Pereira; KLEBIS, Augusta Boa Sorte Oliveira; GEBRAN, Raimunda Abou. O papel das representações sociais na construção da identidade docente. Colloquium Humanarum, Presidente Prudente, v. 14, n. 1, p.86-96 jan/mar 2017. DOI: 10.5747/ch.2017.v14n1.h297.

MIRANDA, Camila Lima; PLACCO, Vera Maria Nigro de Souza; REZENDE, Daisy de Brito. As representações sociais de docência e a constituição identitária de licenciandos em Química. Revista Educação em Questão, Natal, v. 57, n. 54, p. 1-25, e-18085, out./dez. 2019.

MOSCOVICI, Serge. A representação social da psicanálise. Rio de Janeiro: Zahar, 1978. 291p.

MOSCOVICI, Serge. Representações sociais: investigações em psicologia social. 5. ed. Petrópolis: Vozes, 2007. 302 p.

PENIN, Sonia Terezinha Sousa. Cotidiano e Escola: a obra em construção. 2. ed. São Paulo: Cortez, 2011. 208 p.

PIMENTA, Selma Garrido. Saberes pedagógicos e atividade docente. Cortez, 2000.

ROSSI, Adriana Vitorino; FERREIRA, Luiz Henrique. A expansão de espaços para formação de professores de Química: atividades de ensino, pesquisa e extensão a partir da Licenciatura em Química. In: ROSA, Maria Inês Petrucci; ROSSI, Adriana Vitorino (org). Educação Química no Brasil: memórias, políticas e tendências. 2 ed. Campinas: Átomo, 2012. p.126142. 294p. 
SANTOS, Wildson Luiz Pereira dos. A química e a formação para a cidadania. Educación química, vol. 22, n. 4, México, 2011.

SILVA, Amanda Moreira da. A uberização do trabalho docente no brasil: uma tendência de precarização no século XXI. Revista Trabalho Necessário, v.17, nº 34, set-dez. 2019.

SILVA, Rejane M. Ghisolfi; SCHNETZLER, Roseli Pacheco. Constituição de professores universitários de disciplinas sobre ensino de Química. Química Nova, v. 28, n. 6, 2005. Disponível em: https://doi.org/10.1590/S0100-40422005000600030. Acessado em: 30 ago. 2021.

SOUZA, João Valdir Alves; DINIZ, Margareth; OLIVEIRA, Maria Gomes. Formação de Professores (a) e condição docente. Belo Horizonte: UFMG: 2014 p. 09-12.

TARDIF, M. Saberes docentes e formação profissional. Petrópolis: Vozes, 2002.

VASCONCELOS, Sinaida Maria; RESQUE, Marciléa Serrão; BARROS, Maricilda Nazaré Raposo de. Ser professor: representação social e identidade docente. In: Congresso Nacional de Educação. EDUCERE, 12. 2015. Paraná, PUCPR.

VOGEL, Marcos. Influências do PIBID na Representação Social de licenciandos em Química sobre ser "professor de Química". 2016. Tese de Doutorado. Faculdade de Educação, Instituto de Física, Instituto de Química e Instituto de Biociências, Universidade de São Paulo. 220p.

WENZEL, Judite Scherer; ZANON, Lenir Basso; MALDANER, Otavio Aloisio. A constituição do professor pesquisador pela apropriação dos instrumentos culturais do fazer pesquisa. In: ECHEVERIA, Agustinha Rosa; ZANON, Lenir Basso. Formação superior em química no Brasil: práticas e fundamentos curriculares. Ijuí: Unijuí, 2010. p. 67-91. 272p.

ZANON, Lenir Basso; FRISON, Marli Dallagnol; MALDANER, Otavio Aloisio. A. Articulação Entre desenvolvimento curricular e formação inicial de professores de Química. In: ECHEVERIA, Agustinha Rosa; ZANON, Lenir Basso. Formação superior em química no Brasil: práticas e fundamentos curriculares. Ijuí: Unijuí, 2010. p. 201-223. 272p.

Recebido em agosto de 2021.

Aprovado em outubro de 2021. 